\title{
Hodgkin's Disease, Lymphocyte Depletion, Reticular
}

National Cancer Institute

\section{Source}

National Cancer Institute. Hodgkin's Disease, Lymphocyte Depletion, Reticular. NCI

Thesaurus. Code C66847.

A lymphocyte depleted Hodg kin lymphoma characterized by the presence of reticular fibrosis. 